\section{Insight in psychosis and neuropsychological}

\section{function}

\author{
Meta-analysis
}

\author{
ANDRÉ ALEMAN, NIRUJ AGRAWAL, KEVIN D. MORGAN \\ and ANTHONY S. DAVID
}

\author{
Background One factor contributing \\ to impaired awareness of illness (poor \\ insight) in psychotic disorders may be \\ neurocognitive deficits.
}

\begin{abstract}
Method A systematic review and meta-analysis were conducted after data extraction. Following an overall analysis, in which measures of different cognitive domains were taken together, more finegrained analyses investigated whether there was a specific relation with frontal executive functioning, and whether this was influenced by diagnosis or the insight scales used.
\end{abstract}

Results There was a significant mean correlation between insight ratings and neurocognitive performance (mean weighted $r=0.17,95 \% \mathrm{Cl} 0.13-0.21, z=8.3$, $P<0.000$ I), based on 35 studies with a total of 2354 individuals. Further analyses revealed that the effect of general intellectual impairment was smaller than the specific association with executive function. This was only the case for psychosis in general, and not in an analysis limited to schizophrenia, where all cognitive domains were associated with impaired insight to a similar degree.

\section{Conclusions Neuropsychological dys- function, specifically impairment of set- shifting and error monitoring, contributes to poor insight in psychosis. Specific relations with different dimensions of insight and the putative role of meta- cognitive functions require further study.}

Declaration of interest None. Funding detailed in Acknowledgement.
Lack of insight (i.e. poor awareness of illness) is a common feature of schizophrenia, and indeed of psychosis in general (Amador \& David, 2004). Impaired insight is of clinical importance, as it has been linked to poor treatment compliance (Kemp \& David, 1997), poorer global functioning (Pyne et al, 2001), severity of psychopathology (Mintz et al, 2003), recurrence, and poorer outcome (David et al, 1995). As early as 1934 impaired insight was argued to arise from a neuropsychological deficit (Lewis, 1934; David, 1999), although others maintain that 'poor insight' should not be conceived of solely as a defect within the individual but more as a sociocultural response (see Saravanan et al, 2004). Empirical testing of the neuropsychological hypothesis has only occurred over the past decade. In particular, it has been proposed that impaired functioning of the prefrontal cortex, which subserves mental flexibility, abstract reasoning, concept formation and self-reflection, may lead to impaired insight (David, 1990). Although numerous studies report unawareness of illness to be associated with dysfunction on several neuropsychological tests (Morgan \& David, 2004), the findings are inconsistent. For example, although an association of insight with performance on the Wisconsin Card Sorting Test (WCST) has repeatedly been reported (e.g. Young et al, 1993; Rossell et al, 2003), a number of studies have failed to replicate such a relationship (e.g. Cuesta et al, 1995; Dickerson et al, 1997).

In this paper we present meta-analyses of insight and cognition studies, in order to synthesise and integrate the published findings, and to estimate the magnitude of any association. Furthermore, we test the hypothesis whether insight is related to general intellectual dysfunction (e.g. IQ score) or more specifically to prefrontal cognitive dysfunction (e.g. WCST performance). Separate analyses are conducted for samples with a diagnosis of schizophrenia (as opposed to other psychoses) because schizophrenia has been associated with substantial cognitive impairment (Heinrichs \& Zakzaknis, 1998; Aleman et al, 1999). Finally, insight is a multidimensional construct, and measures of insight vary considerably, ranging from 1 to 74 items (Amador \& Kronengold, 2004). Therefore, we address the issue whether different components of the insight construct and different measures thereof moderate the insight-cognition relationship.

\section{METHOD}

\section{Study selection}

Articles for consideration were identified using a three-step procedure. First, a literature search was conducted in the electronic databases PubMed and Web of Science in the period between 1980 and April 2004, using the keywords INSIGHT or UNAWARENESS combined with PSYCHOSIS or SCHIZOPHRENIA combined with COGNITI* or NEUROPSYCHOLOG* or INTELLIGENCE, MEMORY or WCST. This yielded 215 papers, of which 33 fulfilled our criteria (see below). Studies were included after consensus was reached between two authors (A.A. and N.A.) that the paper met all inclusion criteria. Second, we screened the reference list of a recent review by Morgan \& David (2004), which yielded two additional papers for inclusion in the meta-analysis (Takai et al, 1992; Goldberg et al, 2001). Finally, in order not to miss new articles that might not yet have been electronically indexed, a hand search of key journals was conducted for the period April 2003 to April 2004; this included the American Journal of Psychiatry, Archives of General Psychiatry, British Journal of Psychiatry, Journal of Nervous and Mental Disease, Psychiatry Research, Psychological Medicine, Schizophrenia Bulletin and Schizophrenia Research. This did not yield any additional paper suitable for inclusion.

To be included in the meta-analysis, studies had to report correlations between insight scales and cognitive performance measures. In addition, they had to satisfy the following criteria:

(a) the sample comprised patient groups with a psychotic disorder, whether affective or non-affective;

(b) sufficient information was reported to compute effect sizes, or to determine 
the direction and significance of the effect;

(c) the article had been published in a peerreviewed English-language journal.

Studies had to include a valid measure of insight, such as the insight item from the Positive and Negative Syndrome Scale (PANSS; Kay et al, 1987) or Present State Examination (PSE; Wing et al, 1974); the 11-item Schedule for the Assessment of Insight, original and Expanded version (SAI-E; Kemp \& David, 1997; Sanz et al, 1998); the 74-item Scale to Assess Unawareness of Mental Disorder (SUMD; Amador et al, 1993); or the 11-item Insight and Treatment Attitudes Questionnaire (ITAQ; McEvoy et al, 1989).

With regard to the cognitive domains, we defined five domains. The first was total cognition, in which all cognitive test results published in the same paper were pooled. Examples of such tests are the Wechsler Adult Intelligence Scale (WAIS), or subtests of the WAIS such as Digit Span; the Mini-Mental State Examination (MMSE); the National Adult Reading Test (NART); the Trail Making Test; the Wisconsin Card Sorting Test (WCST); and measures of attention, memory tests and verbal fluency tests (see Lezak, 1995 for a description of these measures). The second domain was IQ only, which in most cases pertained to the WAIS. Other estimates of intelligence with an established validity were also included. In cases where only a number of WAIS sub-tests were included, these subtests were pooled. The third domain, memory, included established measures of verbal and visual memory performance (see Aleman et al, 1999). Fourth was frontal executive function, which included the Trail Making Test B, verbal fluency and the WCST. Finally, a separate analysis limited to the WCST was included, because several authors have postulated a specific relationship between perseveration as assessed by the WCST and poor insight (cf. Morgan \& David, 2004). Furthermore, in a construct validation factor analysis (involving data from 473 clinical cases) WCST scores loaded independently of other neuropsychological variables, indicating that the WCST contributes uniquely to neuropsychological evaluation (Greve et al, 1998). For the WCST analysis we included categories completed as well as perseverative responses, which were pooled when both were reported in a single paper (cf. Nieuwenstein et al, 2001). These parameters of the WCST have been shown to load on the same factor, termed 'perseveration' (Cuesta et al, 1995).

\section{Data analysis}

For each study an effect size was calculated, which was the mean $r$ weighted for sample size (Hunter \& Schmidt, 1990). When the precise $r$ values were not given, an estimate was computed from exact $P, t$ or $F$ values (Lipsey \& Wilson, 2001). A problem in meta-analysis concerns the handling of missing values owing to studies reporting that a result was non-significant without providing the exact statistics. The most common method is to exclude such studies completely; this is unfortunate, and will bias the results considerably when there is a substantial number of studies with this problem (as in the present case). Another method is to give such studies values of $r=0$, which is a highly conservative approach that may obscure the existence of small effects. A third method is to assign such studies the mean effect size of the studies that report an insignificant effect size. A problem of this method is that it may yield an overestimation of the nonsignificant effect sizes (as authors will more readily report non-significant effect sizes of some magnitude than very small ones). A reasonable compromise, in our view, is to include the lowest value of the $95 \%$ confidence interval of the mean effect size for non-significant studies that do report precise statistics. This is a conservative approach, but not as extremely conservative as the zero substitution approach. We adopted this strategy for the overall analysis, to be able to include as many informative papers as possible. After computing effect sizes for each study we applied meta-analytic methods in order to obtain a combined effect size, which indicated the magnitude of the association across all studies (cf. Nieuwenstein et al, 2001). Effect sizes were weighted for sample size, in order to correct for upwardly biased estimation of the effect in small sample sizes (Rosenthal, 1991). The corresponding $z$-value and significance level provide an indication of the statistical significance of the association. We also calculated a homogeneity statistic, $Q$, to test whether the studies can be taken to share a common population effect size. A significant $Q$ statistic indicates heterogeneity of the individual study effect sizes which poses a threat to a reliable interpretation of the results. However, when a small number of studies are included in the meta-analysis, the $Q$ statistic can underreport heterogeneity, and an exploration of heterogeneity is warranted through subgroup analyses. All analyses were carried out in the random-effects model, using the Comprehensive Meta-Analysis package (see http://www.meta-analysis.com). In contrast to the fixed-effects model, the random-effects model permits generalisation to studies not yet in the sample, and is to be preferred when studying psychiatric phenomena which may be not only empirically but also conceptually heterogeneous (Rosenthal \& DiMatteo, 2001).

\section{RESULTS}

Characteristics of studies included in the meta-analyses are listed in Table 1 . The first analyses concerned studies reporting on psychosis in general. Tables 2 and 3 show all results for these analyses. The mean weighted effect size for the relationship between insight and all cognitive measures pooled together was $r=0.17$ (95\% CI $0.13-0.21, z=8.3, P<0.0001$ ). This concerned the results of 35 studies with a total of 2354 individuals. The effect sizes were not heterogeneous between studies. For IQ measures, the mean weighted effect size was $r=0.14 \quad(20$ studies). The effect size for memory measures was small and non-significant: $r=0.08, z=1.3, P<0.19$ (10 studies). For measures of frontal executive function, the mean weighted effect size was $r=0.19$ (21 studies), whereas an analysis limited to the WCST revealed an effect size of $r=0.23$ (13 studies). The difference between the effect sizes for IQ and WCST was significant $\left(Q_{\mathrm{B}}=6.4 ; P=0.01\right)$, as was the difference between frontal executive function and memory $\left(Q_{\mathrm{B}}=4.1 ; P=0.04\right)$. Other comparisons were not significant. Figures 1-3 show forest plots of the analyses for total cognition, IQ and WCST respectively.

The next analyses were confined to studies reporting on samples of patients with a diagnosis of schizophrenia made using explicit diagnostic criteria. Mean effect sizes for insight-cognition relationships were in the small to medium range, and varied from 0.19 (executive function) to 0.28 (memory). The effect sizes did not differ significantly 
Table I Characteristics of studies included in the meta-analyses

\begin{tabular}{|c|c|c|c|c|c|c|}
\hline Study & $n^{\prime}$ & Diagnosis & $\begin{array}{l}\text { Age, years } \\
\text { Mean (s.d.) }\end{array}$ & $\begin{array}{l}\text { Number of } \\
\text { hospitalisations } \\
\text { Mean }\end{array}$ & Insight scale & Cognitive measures \\
\hline Aleman et al (2002) & 38 & Schizophrenia & - & - & PANSS & $\begin{array}{l}\text { Working memory (digit span, visual } \\
\text { elevator task), source memory }\end{array}$ \\
\hline Almeida et al (1996) & 40 & Late paraphrenia & - & - & SAI, PSE & $\begin{array}{l}\text { NART, digit and spatial span, RMT, visual } \\
\text { fluency test }\end{array}$ \\
\hline Arduini et al (2003) & 64 & $\begin{array}{l}\text { Schizophrenia }(n=42) \\
\text { Bipolar disorder }(n=22)\end{array}$ & $37(12)$ & - & SUMD & WCST \\
\hline Buckley et al (200I) & 50 & Schizophrenia & $42(9)$ & - & SUMD & Luria-Nebraska test, TMT A, B \\
\hline Carroll et al (1999) & 100 & Schizophrenia & $36(11)$ & - & ITAQ & $\begin{array}{l}\text { Rivermead behavioural memory test, } \\
\text { Quick Test for IQ, NART }\end{array}$ \\
\hline Chen et al (200I) & 80 & $\begin{array}{l}\text { Schizophrenia }(n=55) \\
\text { Bipolar disorder, mania } \\
(n=10) \\
\text { Other psychoses }(n=15)\end{array}$ & 34.5 & - & SUMD & WCST \\
\hline Collins et al (1997) & 58 & Schizophrenia & $34.1(8)$ & - & SAI & WCST \\
\hline $\begin{array}{l}\text { Cuesta \& Peralta } \\
\text { (1994) }\end{array}$ & 40 & Schizophrenia & $28(8)$ & - & $\begin{array}{l}\text { AMDP (items 97-99), } \\
\text { Global LII }\end{array}$ & $\begin{array}{l}\text { MMSE, WAIS, Luria's test of premotor } \\
\text { praxias, Rey complex figure, TMT A, B, } \\
\text { Bender visual motor tests }\end{array}$ \\
\hline Cuesta et al (1995) & 52 & $\begin{array}{l}\text { Schizophrenia }(n=35) \\
\text { Schizoaffective } \\
\text { disorder }(n=10) \\
\text { Bipolar disorder, } \\
\text { mania }(n=7)\end{array}$ & $31(8)$ & - & $\begin{array}{l}\text { Manual for assessment } \\
\text { and documentation of } \\
\text { psychopathology }\end{array}$ & WCST \\
\hline David et al (1992) & 91 & $\begin{array}{l}\text { Schizophrenia }(n=52) \\
\text { Other psychoses }\end{array}$ & $31(10)$ & 3.3 & SAI, PSE & NART \\
\hline David et al (1995) & 150 & $\begin{array}{l}\text { Schizophrenia } \\
\text { Other psychoses }\end{array}$ & $26(7)$ & - & SAI, PSE & $\begin{array}{l}\text { NART, Igar Scale (brief cognitive screen, } \\
\text { TMT, motor sequencing, set maintenance } \\
\text { and shift) }\end{array}$ \\
\hline Dickerson et al (1997) & 87 & $\begin{array}{l}\text { Schizophrenia }(n=54) \\
\text { Schizoaffective } \\
\text { disorder }(n=33)\end{array}$ & $39(10)$ & 5.6 & PANSS & $\begin{array}{l}\text { WAIS-R ( } 5 \text { sub-tests), logical memory } \\
\text { test of WMS-R, WCST, TMT, Rey- } \\
\text { Osterrieth complex figure test, } \\
\text { Halstead-Wepman aphasia screening, } \\
\text { Chicago word fluency test }\end{array}$ \\
\hline Drake \& Lewis (2003) & 33 & $\begin{array}{l}\text { Schizophrenia }(n=16) \\
\text { Schizophreniform, } \\
\text { schizoaffective } \\
\text { disorder }\end{array}$ & $\begin{array}{l}29 \text { (range } \\
19-61)\end{array}$ & - & $\begin{array}{l}\text { PANSS, SAI-E, ITAQ, } \\
\text { SUMD }\end{array}$ & $\begin{array}{l}\text { Theory of mind, abstraction (sentences } \\
\text { test, triads test), set-shifting (TMT B, } \\
\text { Hayling test, Frontal Lobe Score, Brixton } \\
\text { test) }\end{array}$ \\
\hline Fennig et al (1996) & 189 & $\begin{array}{l}\text { Schizophrenia }(n=60) \\
\text { Bipolar disorder }(n=52) \\
\text { Other psychoses }\end{array}$ & $15-60$ & - & $\begin{array}{l}\text { Modified insight item } \\
\text { of HRSD }\end{array}$ & Quick Test for IQ \\
\hline Flashman et al (2000) & 29 & $\begin{array}{l}\text { Schizophrenia } \\
\text { spectrum }\end{array}$ & $35(12)$ & - & SUMD & Full-scale IQ \\
\hline Ghaemi et al (1996) & 16 & Acute mania & $37(13)$ & 6 & ITAQ & $\begin{array}{l}\text { Full-scale IQ, similarities, memory pas- } \\
\text { sages recall, visual reproduction recall }\end{array}$ \\
\hline Goldberg et al (200I) & 146 & $\begin{array}{l}\text { Schizophrenia } \\
\text { spectrum }\end{array}$ & $4 I(9)$ & 11.6 & PANSS & RBANS, WCST, WRAT-R, WAIS III \\
\hline Kemp \& David (1996) & 74 & $\begin{array}{l}\text { Schizophrenia }(n=47) \\
\text { Other psychoses }\end{array}$ & $35(\mathrm{II})$ & 4.3 & SAI, PSE & $\begin{array}{l}\text { NART, verbal fluency test, cognitive } \\
\text { estimate test, TMT }\end{array}$ \\
\hline Laroi et al (2000) & 21 & Schizophrenia & $36(10)$ & - & SUMD & $\begin{array}{l}\text { WCST, WAIS-R (block design and } \\
\text { vocabulary), TMT, Kimura figures test }\end{array}$ \\
\hline
\end{tabular}


Table I (continued)

\begin{tabular}{|c|c|c|c|c|c|c|}
\hline Study & $n$ & Diagnosis & $\begin{array}{l}\text { Age, years } \\
\text { mean (s.d.)' }\end{array}$ & $\begin{array}{l}\text { Number of } \\
\text { hospitalisations } \\
\text { Mean }\end{array}$ & Insight scale & Cognitive measures \\
\hline Lysaker \& Bell (1994) & 92 & $\begin{array}{l}\text { Schizophrenia } \\
\text { Schizoaffective disorder }\end{array}$ & $44(10)$ & 8.5 & PANSS & WCST \\
\hline Lysaker et al (2002) & 132 & $\begin{array}{l}\text { Schizophrenia }(n=87) \\
\text { Schizoaffective disorder } \\
(n=45)\end{array}$ & $43(9)$ & 8.1 & SUMD & WAIS III, WCST \\
\hline $\begin{array}{l}\text { Macpherson et al } \\
\text { (1996) }\end{array}$ & 64 & Schizophrenia & - & - & SAI & MMSE, NART \\
\hline Marks et al (2000) & 59 & $\begin{array}{l}\text { Schizophrenia }(n=42) \\
\text { Schizoaffective disorder } \\
(n=17)\end{array}$ & $43($ II) & - & SUMD, PANSS, SAIQ & $\begin{array}{l}\text { WCST, Stroop test, } \\
\text { Similarities, letter number sequencing, } \\
\text { Hopkins verbal learning test, logical } \\
\text { memory I of WMS-R, NART }\end{array}$ \\
\hline McCabe et al (2002) & 89 & Schizophrenia & $40(12)$ & 8.9 & SAI & $\begin{array}{l}\text { Luria-Nebraska neuropsychological } \\
\text { battery }\end{array}$ \\
\hline McEvoy et al (1996) & 32 & $\begin{array}{l}\text { Schizophrenia }(n=26) \\
\text { Other psychoses }\end{array}$ & $34(10)$ & 6 & ITAQ & $\begin{array}{l}\text { WCST, vocabulary block and design } \\
\text { (WAIS), figural fluency test, controlled } \\
\text { word association test, finger localisation, } \\
\text { right-left disorientation, judgement of } \\
\text { line orientation, Rey-Osterrieth } \\
\text { complex figure test }\end{array}$ \\
\hline Mohamed et al (1999) & 46 & Schizophrenia & $36(10)$ & - & SUMD & $\begin{array}{l}\text { WCST, WAIS-R, TMT, verbal fluency } \\
\text { test, design fluency test }\end{array}$ \\
\hline Rossell et al (2003) & 78 & Schizophrenia & $34(9)$ & - & SAI-E & $\begin{array}{l}\text { WAIS-R (short version), WCST, } \\
\text { continuous performance test controlled } \\
\text { oral word association test }\end{array}$ \\
\hline Sanz et al (1998) & 33 & $\begin{array}{l}\text { Schizophrenia (55\%) } \\
\text { Other psychoses }\end{array}$ & $32(8)$ & 3.5 & ITAQ, SAI, PANSS & $\begin{array}{l}\text { MMSE, NART, WCST, TMT, Star calcula- } \\
\text { tion test }\end{array}$ \\
\hline Smith et al (2000) & 46 & $\begin{array}{l}\text { Schizophrenia }(n=26) \\
\text { Schizoaffective disorder } \\
(n=20)\end{array}$ & $39(12)$ & 7.7 & SUMD & $\begin{array}{l}\text { WAIS-R ( } 3 \text { sub-tests), DSDT, California } \\
\text { verbal learning test, WCST, verbal } \\
\text { fluency test, Benton facial recognition } \\
\text { test }\end{array}$ \\
\hline Startup (1997) & 28 & Schizophrenia & $4 \mathrm{I}(\mathrm{II})$ & 6.2 & ITAQ & Spot the word test \\
\hline Takai et al (1992) & 57 & Schizophrenia & $39(9)$ & 3.7 & PSE & WAIS \\
\hline $\begin{array}{l}\text { Upthegrove et al } \\
\text { (2002) }\end{array}$ & 30 & Schizophrenia & $\begin{array}{l}35 \text { (range } \\
18-60)\end{array}$ & - & SAI-E & Digit span, wording memory \\
\hline Vaz et al (2002) & 82 & Schizophrenia & $35(9)$ & 3.5 & SAI & Cognitive factor of the PANSS ${ }^{3}$ \\
\hline Young et al (1993) & 31 & Schizophrenia & 38.7 & 16.2 & SUMD & $\begin{array}{l}\text { WCST, verbal fluency test, TMT A, B, } \\
\text { WAIS-R }\end{array}$ \\
\hline Young et al (1998) & 108 & Schizophrenia & - & - & & WCST, WAIS-R \\
\hline
\end{tabular}

AMDP, Manual for the Assessment and Documentation of Psychopathology; DSDT, Digit Span Distractibility Test; HRSD, Hamilton Rating Scale for Depression; ITAQ, Insight and Treatment Attitude Questionnaire; LII, Lack of Insight Index; MMSE, Mini-Mental State Examination; NART, National Adult Reading Test; PANSS, Positive and Negative Syndrome Scale; PSE, Present State Examination; RBANS, Repeatable Battery for Assessment of Neuropsychological Status; RMT, Recognition Memory Test; SAI(-E), Schedule for the Assessment of Insight (Extended version); SUMD, Scale to Assess Unawareness of Mental Disorder; TMT, Trail Making Test; WAIS, Wechsler Adult Intelligence Scale; WCST, Wisconsin Card Sorting Test; WMS-R, Wechsler Memory Scale - Revised; WRAT-R, Wide Range Achievement Test - Reading.

I. Numbers in this column are those reported at the start of the Method section of the papers concerned; the numbers included in our statistical analysis may be smaller owing to drop-outs.

2. Dashes indicate data are not available.

3. The cognitive factor of the PANSS correlates well with neuropsychological performance (Bell et al, 1994) and was therefore included in the overall analysis.

from each other. Thus, in contrast to the first analysis for psychosis in general, the WCST-insight relationship was not stronger than the IQ-insight relationship. In addition, the correlation between memory performance and insight was significant in this analysis limited to schizophrenia, but not in the first analysis including psychosis in general. Table 2 lists all results for these analyses.

Finally, associations of different insight scales with cognition were examined 
Table 2 Results of meta-analyses on insight-cognition relationships in samples of patients with (a) psychosis and (b) with a diagnosis of schizophrenia

\begin{tabular}{|c|c|c|c|c|c|c|c|c|}
\hline & $\begin{array}{c}\text { Studies' } \\
n\end{array}$ & $\begin{array}{c}\text { Participants }^{2} \\
n\end{array}$ & $R^{3}$ & $95 \% \mathrm{Cl}$ & $Z^{4}$ & $P$ & $Q_{(w)}{ }^{5}$ & $P$ \\
\hline \multicolumn{9}{|l|}{ Psychosis } \\
\hline Total cognition & 35 & 2354 & 0.17 & 0.13 to 0.21 & 8.3 & $<0.0001$ & 30.2 & 0.65 \\
\hline IQ & 20 & 1385 & 0.14 & 0.09 to 0.19 & 5.1 & $<0.0001$ & 7.1 & 0.99 \\
\hline Memory & 10 & 477 & 0.08 & -0.04 to 0.21 & 1.3 & 0.19 & 14.6 & 0.10 \\
\hline Executive function & 21 & 1472 & 0.19 & 0.14 to 0.24 & 7.1 & $<0.0001$ & I5.I & 0.77 \\
\hline WCST & 13 & 712 & 0.23 & 0.16 to 0.30 & 6.1 & $<0.0001$ & 11.2 & 0.51 \\
\hline \multicolumn{9}{|l|}{ Schizophrenia } \\
\hline Total cognition & II & 660 & 0.23 & 0.15 to 0.30 & 5.8 & $<0.0001$ & 4.8 & 0.91 \\
\hline IQ & 4 & 174 & 0.26 & 0.12 to 0.40 & 3.4 & $<0.001$ & 0.6 & 0.89 \\
\hline Memory & 3 & 129 & 0.28 & 0.11 to 0.43 & 3.2 & 0.002 & I.I & 0.58 \\
\hline Executive function & 5 & 331 & 0.19 & 0.08 to 0.30 & 3.3 & 0.001 & 0.50 & 0.97 \\
\hline WCST & 5 & 311 & 0.25 & 0.14 to 0.36 & 4.2 & $<0.0001$ & 4.3 & 0.37 \\
\hline
\end{tabular}

I. Number of studies included in the analysis.

2. Total number of participants across studies.

3. Mean weighted correlation coefficient; $95 \% \mathrm{Cl}=95 \%$ confidence interval;

4. Fisher's $Z$, and significance of effect size $(P)$

5. Within-category heterogeneity between studies.

WCST, Wisconsin Card Sorting Test.

Table 3 Different insight scales and mean correlations with neuropsychological function across studies

\begin{tabular}{|c|c|c|c|c|c|c|c|c|}
\hline & $\begin{array}{c}\text { Studies } \\
n\end{array}$ & $\begin{array}{c}\text { Participants }^{2} \\
n\end{array}$ & $\mathrm{R}^{3}$ & $95 \% \mathrm{Cl}$ & $Z^{4}$ & $P$ & $Q_{(w)}^{5}$ & $P$ \\
\hline \multicolumn{9}{|c|}{ Total cognition } \\
\hline SAI & 10 & 754 & 0.21 & 0.14 to 0.28 & 5.7 & $<0.0001$ & 7.4 & 0.60 \\
\hline SUMD & 10 & 599 & 0.19 & 0.11 to 0.27 & 4.5 & $<0.0001$ & 3.5 & 0.94 \\
\hline ITAQ & 3 & 160 & 0.28 & 0.12 to 0.42 & 3.5 & 0.0005 & 1.0 & 0.60 \\
\hline PANSS & 4 & 363 & 0.15 & 0.05 to 0.25 & 2.8 & 0.005 & 2.4 & 0.49 \\
\hline \multicolumn{9}{|l|}{ WCST } \\
\hline SAI & 3 & 228 & 0.14 & -0.01 to 0.29 & 1.8 & 0.07 & 0.2 & 0.92 \\
\hline SUMD & 6 & 308 & 0.28 & 0.13 to 0.42 & 3.7 & 0.0004 & 7.9 & 0.16 \\
\hline
\end{tabular}

ITAQ, Insight and Treatment Attitude Questionnaire; PANSS, Positive and Negative Syndrome Scale; SAI, Schedule for the Assessment of Insight; SUMD, Scale to Assess Unawareness of Mental Disorder; WCST, Wisconsin Card Sorting Test.

I. Number of studies included in the analysis.

2. Total number of participants across studies.

3. Mean weighted correlation coefficient.

4. Fisher's $Z$, and significance of effect size $(P)$.

5 . Within-category heterogeneity between studies.

(including studies that reported on psychosis in general). These analyses focused on the four scales that have most been used (Morgan \& David, 2004), all of which showed significant correlations with total cognition (Table 3). With regard to associations with general cognition, mean correlations varied from 0.15 (PANSS) to 0.28 (ITAQ). The differences in magnitude of effect size did not attain significance, however. For the WCST the mean correlation with the SUMD was 0.28 , whereas the correlation with the SAI was 0.14 . Again, is a funnel plot of the studies included in the primary analysis: this is a scatterplot of the effect size by sample size of each study, which should take the shape of a funnel, as there should be greater variability among the effect sizes based on small samples than those based on large samples (Wang \& Bushman, 1998). The underrepresentation of small studies with small effects could be indicative of publication bias. Figure 4 shows that such studies are indeed somewhat underrepresented, but the asymmetry is not strong. To assess whether sampling bias would be large enough to render the mean effect size insignificant, we computed an additional statistic, the fail-safe $n$ (Orwin, 1983; Rosenthal, 1991). Specifically, we determined the number of studies with an effect size of zero needed to reduce the mean effect size to a negligible effect $(\mathrm{r}=0.05)$. The fail-safe $n$ was 84 for the overall analysis (35 studies) and 40 for the analysis confined to the diagnosis of schizophrenia (11 studies). It is unlikely that such a large number of unpublished studies with null effects reside in file drawers.

\section{DISCUSSION}

Several findings emerge from our metaanalysis of published neuropsychological studies of insight in patients with psychotic disorders. First, insight showed a small, albeit statistically significant, positive relationship with general cognitive functioning. Second, the relationship between WCST performance and insight was significantly stronger than the association with IQ, with a magnitude corresponding to a medium effect size (Cohen, 1988). Third, whereas the WCST-insight association was stronger than the IQ-insight association in samples of patients with psychotic disorders in general, there was no difference between these associations when analyses were limited to samples of patients with a diagnosis of schizophrenia. Overall, however, the insight-cognition assessment was slightly stronger in patients with schizophrenia $v$. patients with psychosis in general. Finally, analyses of different insight scales did not reveal significant differences in their association with cognitive performance. analytic findings is the possibility of an upward bias of the mean effect due to the omission of unpublished studies with null effects. Small studies with significant results tend to be published, whereas small studies without statistically significant findings tend to remain in the file drawer. Figure 4

\section{Neuropsychological dysfunction}

It has been a matter of debate in recent years whether poor insight in psychotic disorders can, in part, be explained by 


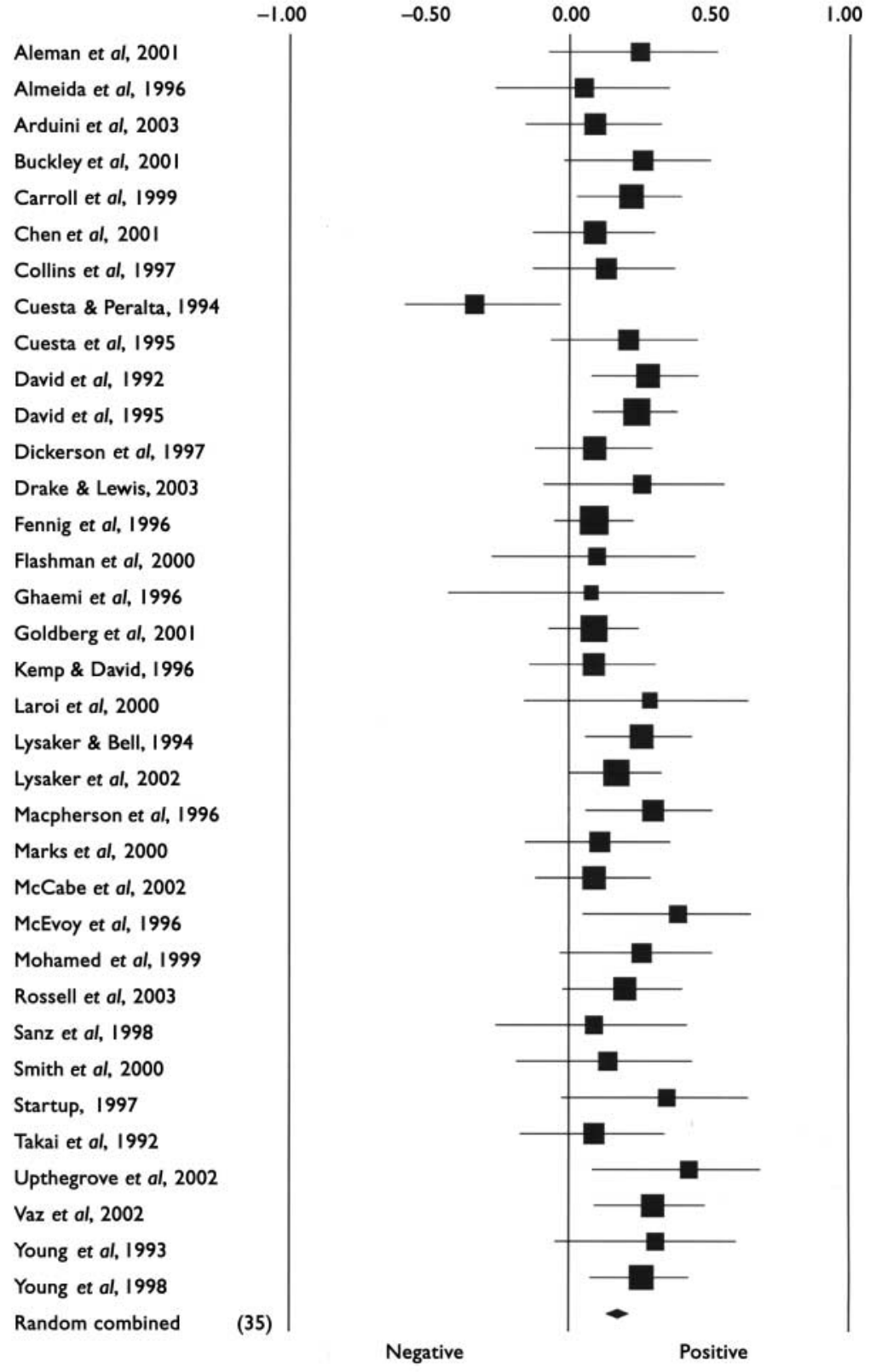

Fig. I Forest plot of studies included in the meta-analysis of the relationship between insight and 'total cognition' (all cognitive tests pooled together).

neuropsychological dysfunction. The association of insight with general cognitive function observed in our meta-analysis may imply that the interpretation and attribution of anomalous mental experiences is indeed hampered by poor general cognition. Notably, although the effect sizes were in the small to medium range, a recent meta-analysis of insight studies reported comparable mean correlations for the association with positive and negative symptoms; Mintz et al (2003) observed a correlation of 0.25 for positive symptoms (based on 22 studies) and a correlation of 0.23 for negative symptoms (based on 20 studies). Hence, it could be argued that poor insight in psychosis is part and parcel of psychopathology and cognitive dysfunction in roughly equal measure. However, although psychotic symptoms have been suggested to be largely independent of cognitive functioning (Nieuwenstein et al, 2001), any conclusion regarding independent contributions of psychopathological disorder and cognitive deficits to impaired insight should be confirmed by a regression model in the same sample. Furthermore, interpretations of association should not assume causality. It is possible that the assessment of insight is confounded by cognition, since a clinician's tendency to infer insight may be coloured by the patient's ability to express complex attitudes and experiences. Independent rating of insight and cognition would minimise this effect.

The finding that in patients with a psychotic disorder the relationship between WCST performance and insight was significantly stronger than the association with IQ may imply a specific role of perseveration. With regard to the cognitive mechanisms of insight, WCST performance has been suggested to be of particular relevance (Drake \& Lewis, 2003). Cognitive flexibility is important, as it refers to the capacity 'to hold an abstract representation related to an actual situation, but different from it, at the same time as the more obvious immediate representation' (Drake \& Lewis, 2003). This capacity would enable people to evaluate their own perceptions, thoughts and behaviour in relation to knowledge of symptoms of mental illness (shaped by social and cultural influences). In a sample of 33 people with acute psychosis, Drake $\&$ Lewis (2003) reported a specific strong correlation $(r=0.59)$ between insight and perseverative errors, rather than more general measures of abstraction. This is consistent with the notion that a failure to change cognitive set and to monitor error responses may lead to impaired insight. It should be kept in mind, none the less, that although 'perseveration' is widely recognised as a key cognitive process called upon during WCST performance, the cognitive processes underlying WCST performance remain poorly understood.

\section{Diagnosis of schizophrenia}

Whereas the WCST-insight association was stronger than the IQ-insight association in samples of patients with psychotic disorders in general, there was no difference between these associations when analyses were limited to samples of patients with a diagnosis of schizophrenia. This was not owing to a smaller effect size for WCST, but could be attributed to a larger effect size for IQ in patients with schizophrenia. Schizophrenia involves more negative symptoms and more pronounced intellectual impairment in comparison with other psychotic disorders, and this could lead to a larger correlation between IQ and insight; that is, a certain IQ level might be required to enable the person to make the complex judgements involved in self-reflection and 


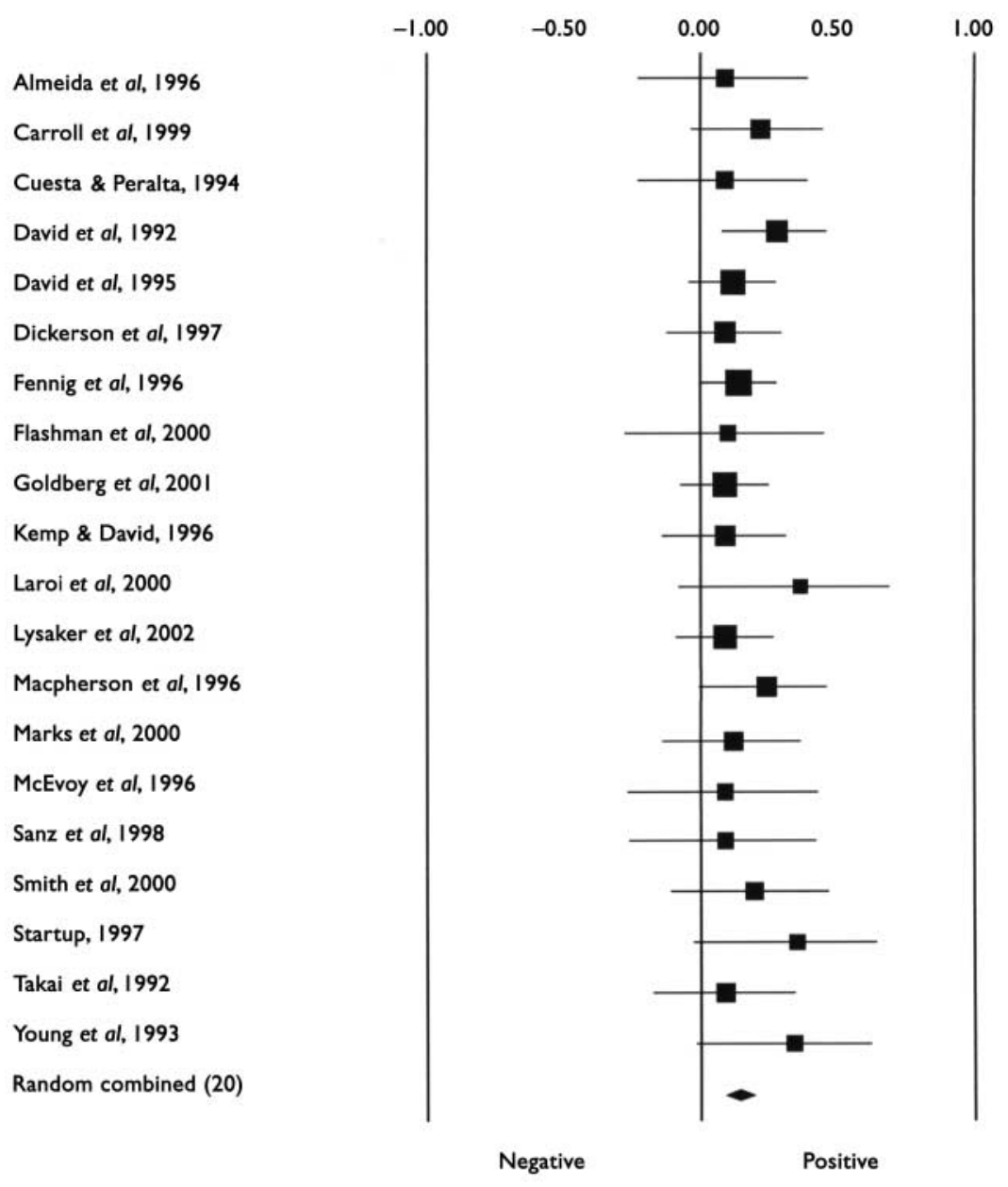

Fig. 2 Forest plot of studies included in the meta-analysis of the relationship between insight and IQ test performance.

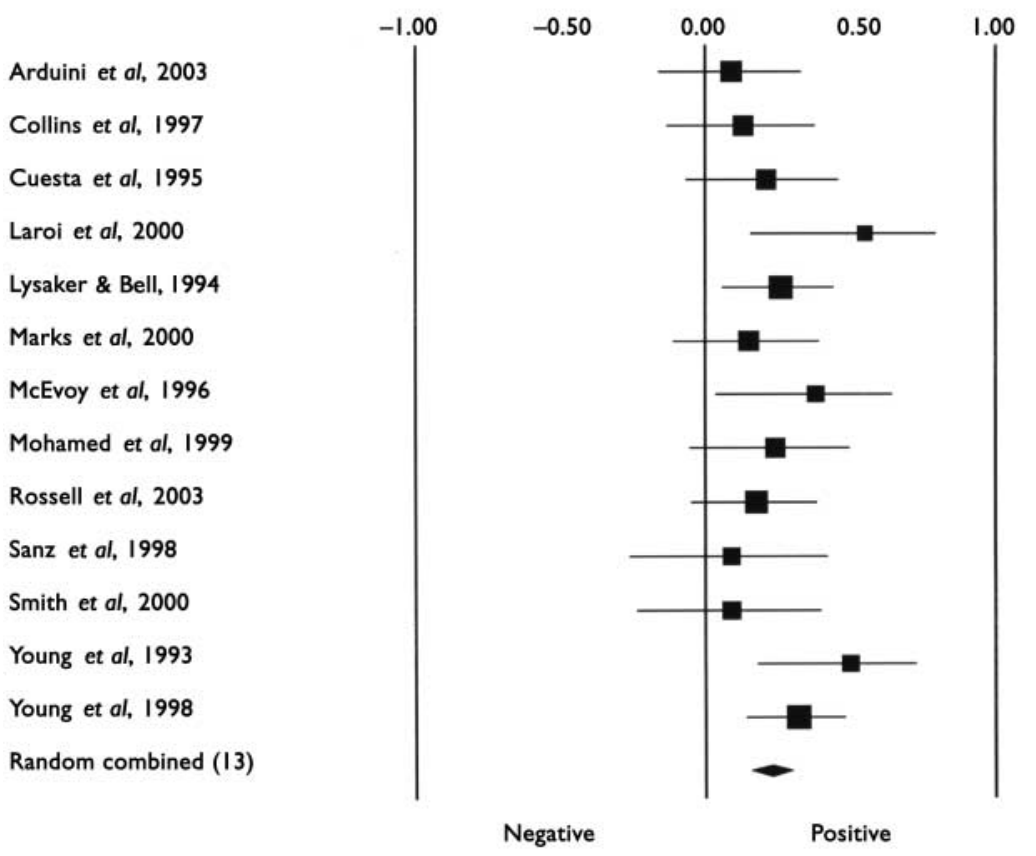

Fig. 3 Forest plot of studies included in the meta-analysis of the relationship between insight and Winsconsin Card Sorting Test performance. monitoring of unusual or ambiguous experiences. Another difference between the analysis confined to schizophrenia proper concerned the relationship between memory performance and insight. This association was significant in schizophrenia, but was absent when all psychoses were included in the analysis. In schizophrenia, large effect sizes of memory impairment have been documented (Aleman et al, 1999) and a certain level of memory function may be necessary for intact insight.

An alternative interpretation of the different results in the analyses including schizophrenia $v$. 'all psychoses' would be that this does not imply a specific role of perseveration in impaired insight, but rather reflects an effect of clinical diagnosis. That is, in patients with less severe psychotic disorders only executive and attentional functioning might be impaired, whereas schizophrenia is characterised by generalised cognitive impairment. Thus, a relationship with insight is found only for cognitive functions that are impaired. Direct comparison between different patient groups is needed to test this possibility. The results of a study published after our meta-analysis was completed may be consistent with this notion (Keshavan et al, 2004): in a sample of 535 patients with first-episode psychosis, the authors observed significant associations of impaired insight with multiple cognitive domains, including memory, learning and executive functions. However, another recent study of a sample comprising 122 out-patients with schizophrenia failed to find significant associations between insight and neuropsychological tests sensitive to frontal lobe function (Freudenreich et al, 2004).

\section{Different scales}

With regard to the use of different insight scales, the PANSS, SAI, SUMD and ITAQ apparently yielded effect sizes in the same range. This is consistent with studies that observed high correlations between these different insight measures (Sanz et al, 1998; Cuesta et al, 2000; Drake \& Lewis, 2003). Unfortunately, owing to the small number of studies reporting separate data for different components of insight scales, it was not possible to analyse differential relations in this regard. It has been suggested that reduced symptom relabelling abilities might be more closely related to deficits in cognitive functioning than other domains of insight such as illness awareness 


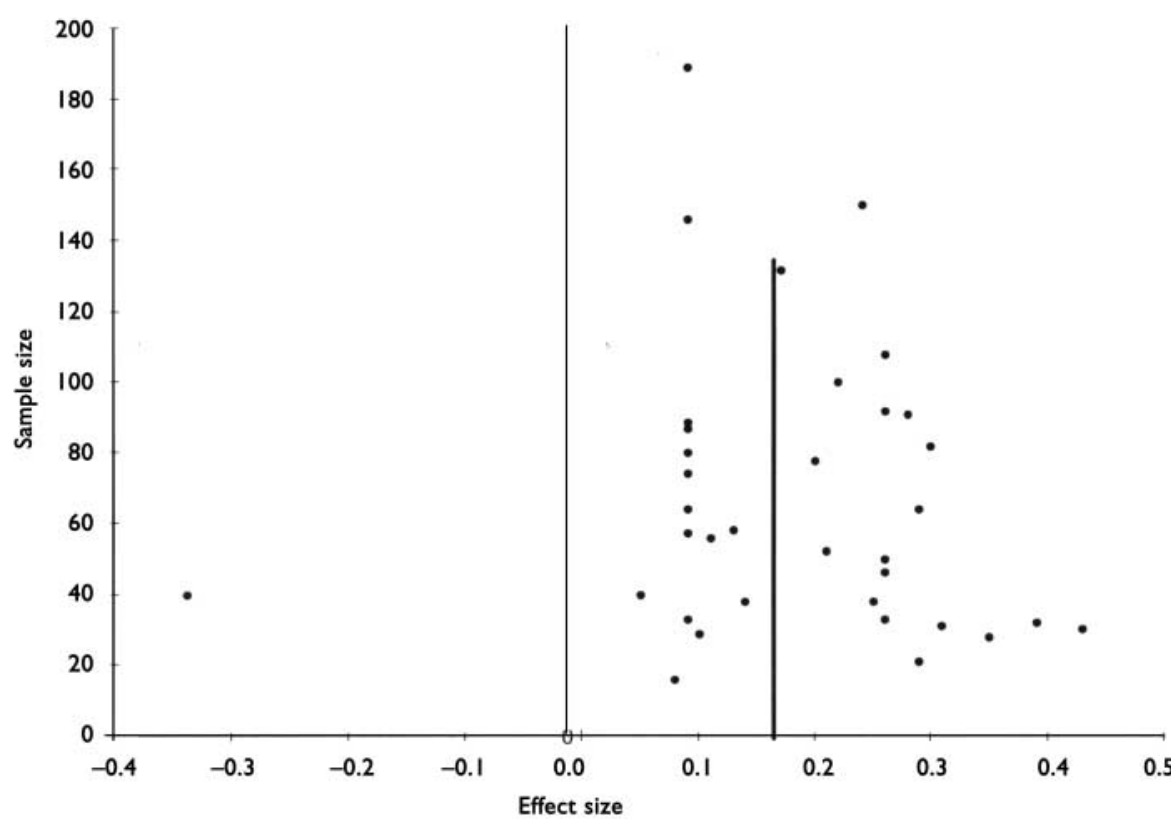

Fig. 4 Funnel plot of the studies included in the primary analysis: the effect size $r$ ( $x$-axis) is plotted against the sample size ( $y$-axis) of each study (the vertical line indicates the mean weighted effect size).

and treatment compliance (Morgan \& David, 2004). The latter components would be less independent of external factors such as social and cultural variations (Saravanan et al, 2004).

A possible explanation for the small and inconsistent correlations observed in a number of studies might be that the relationship between insight and cognitive deficits is non-linear. According to Startup (1996), both motivational and cognitive deficits affect insight, with a trade-off between the two processes, giving rise to quadratic relationships between insight and cognitive test performance. Unfortunately, the other studies included in our meta-analysis did not examine curvilinear associations.

It should be noted that the effect sizes were rather small, implying that cognitive function may explain only a limited portion of the observed variance in insight ratings. The method of meta-analysis has been criticised for mixing dissimilar studies, publication bias and inclusion of poor-quality studies. We addressed these issues by imposing strict inclusion criteria and exploring publication bias. Indeed, as Rosenthal \& DiMatteo (2001) have noted; 'criticisms of meta-analysis that are applicable are equally applicable to traditional, nonquantitative, narrative reviews of the literature'.

Future research should focus more in detail on the role of metacognitive processes, and examine separate components of the insight construct. Koren et al (2004) reported in a sample of 30 patients with first-episode schizophrenia that prediction of poor insight was significantly improved by adding the new, free-choice metacognitive measures to the conventional WCST measures. These preliminary results suggest that metacognition might be an important mediator between basic cognitive deficits and poor insight, and might be even more relevant to poor insight than cognitive deficits per se.

\section{ACKNOWLEDGEMENT}

A.A. was supported by an Innovational Research Grant (016.026.027) from the Netherlands Organisation for Scientific Research.

\section{REFERENCES}

Aleman, A., Hijman, R., De Haan, E. H. F., et al (1999) Memory impairment in schizophrenia: a metaanalysis. American Journal of Psychiatry, 156, 1358-1366.

Aleman, A., De Haan, E. H. F. \& Kahn, R. S. (2002) Insight and neurocognition in schizophrenia. Journal of Neuropsychiatry and Clinical Neurosciences, 14, 241-242.

Almeida, O. P., Levy, R., Howard, R. J., et al (1996) Insight and paranoid disorders in late life (late paraphrenia). International Journal of Geriatric Psychiatry, II, 653-658.

Amador, X. F. \& David, A. S. (eds) (2004) Insight and Psychosis: Awareness of Illness in Schizophrenia and Related Disorders (2nd edn). Oxford: Oxford University Press.

Amador, X. F. \& Kronengold, H. (2004) Understanding and assessing insight. In Insight and
Psychosis (2nd edn) (eds X. F. Amador \& A. S. David), pp. 3-30. Oxford: Oxford University Press.

Amador, X. F., Strauss, D. H., Yale, S. A., et al (1993) Assessment of insight in psychosis. American journal of Psychiatry, 150, 873-879.

Arduini, L., Kalyvoka, A., Stratta, P., et al (2003) Insight and neuropsychological function in patients with schizophrenia and bipolar disorder with psychotic features. Canadian Journal of Psychiatry, 48, 338-341.

Bell, M. D., Lysaker, P. H., Milstein, R. M., et al (1994) Concurrent validity of the cognitive component of schizophrenia - relationship of PANSS scores to neuropsychological assessments. Psychiatry Research, 54, $5 \mathrm{I}-58$.

Buckley, P. F., Hasan, S., Friedman, L., et al (200I) Insight and schizophrenia. Comprehensive Psychiatry, 42, $39-41$.

Carroll, A., Fattah, S., Clyde, Z., et al (1999)

Correlates of insight and insight change in schizophrenia. Schizophrenia Research, 35, 247-253.

Chen, E. Y., Kwok, C. L., Chen, R. Y., et al (200I)

Insight changes in acute psychotic episodes: a prospective study of Hong Kong Chinese patients. Journal of Nervous and Mental Disease, 189, 24-30.

Cohen, J. (1988) Statistical Power Analysis for the Behavioral Sciences (2nd edn). Hillsdale, NJ: Erlbaum.

Collins, A. A., Remington, G. J., Coulter, K., et al (1997) Insight, neurocognitive function and symptom clusters in chronic schizophrenia. Schizophrenia Research, 27, 37-44.

Cuesta, M. J. \& Peralta, V. (1994) Lack of insight in schizophrenia. Schizophrenia Bulletin, 20, 359-366.

Cuesta, M. J., Peralta, V., Caro, F., et al (1995) Is poor insight in psychotic disorders associated with poor performance on the Wisconsin Card Sorting Test? American Journal of Psychiatry, 152, 1380-1382.

Cuesta, M. J., Peralta, V. \& Zarzuela, A. (2000) Reappraising insight in psychosis: multi-scale longitudinal study. British Journal of Psychiatry, 177, 233-240.

David, A. S. (1990) Insight and psychosis. British Journal of Psychiatry, 156, 798-808.

David, A. S. (1999) 'To see oursels as others see us', Aubrey Lewis's insight. British Journal of Psychiatry, $\mathbf{1 7 5}$, 210-216.

David, A., Buchanan, A., Reed, A., et al (1992) The assessment of insight in psychosis. British Journal of Psychiatry, 161, 599-602.

David, A., van Os, J., Jones, P., et al (1995) Insight and psychotic illness. Cross-sectional and longitudinal associations. British Journal of Psychiatry, 167, 621-628.

Dickerson, F. B., Boronow, J. J., Ringel, N., et al (1997) Lack of insight among outpatients with schizophrenia. Psychiatric Services, 48, 195-199.

Drake, R. \& Lewis, S. (2003) Insight and neurocognition in schizophrenia. Schizophrenia Research, 62, 165-173.

Fennig, S., Everett, E., Bromet, E., et al (1996) Insight in first-admission psychotic patients. Schizophrenia Research, 22, 257-263.

Flashman, L. A., McAllister, T.W., Andreasen, N. C., et al (2000) Smaller brain size associated with unawareness of illness in patients with schizophrenia. American Journal of Psychiatry, 157, 1167-1169.

Freudenreich, O., Deckersbach, T. \& Goff, D. C. (2004) Insight into current symptoms of schizophrenia: association with frontal cortical function and affect. Acto Psychiatrica Scandinavica, II0, 14-20. 
Ghaemi, S. N., Hebben, N., Stoll, A. L., et al (1996) Neuropsychological aspects of lack of insight in bipolar disorder: a preliminary report. Psychiatry Research, 65 113-120.

Goldberg, R.W., Green-Paden, L. D., Lehman, A. F., et al (200I) Correlates of insight in serious mental illness. Journal of Nervous and Mental Disease, 189, 137-145.

Greve, K. W., Ingram, F. \& Bianchini, K. J. (1998) Latent structure of the Wisconsin Card Sorting Test in a clinical sample. Archives of Clinical Neuropsychology, I3, 597-609.

\section{Heinrichs, R.W. \& Zakzanis, K. K. (1998)}

Neurocognitive deficit in schizophrenia: a quantitative review of the evidence. Neuropsychology, 12, 426-445.

Hunter, J. E. \& Schmidt, F. L. (1990) Methods of MetaAnalysis: Correcting Error and Bias in Research Findings. Newbury Park, CA: Sage.

Kay, S. R., Fiszbein, A. \& Opler, L. A. (1987) The positive and negative syndrome scale (PANSS) for schizophrenia. Schizophrenia Bulletin, 13, 261-276.

Kemp, R. \& David, A. (1996) Psychological predictors of insight and compliance in psychotic patients. British Journal of Psychiatry, 169, 444-450.

Kemp, R. \& David, A. (1997) Insight and compliance. In Treatment Compliance and the Therapeutic Alliance (ed. B. Blackwell), pp. 6I-84. Amsterdam: Harwood.

Keshavan, M. S., Rabinowitz, J., DeSmedt, G., et al (2004) Correlates of insight in first episode psychosis. Schizophrenia Research, 70, 187-194.

Koren, D., Seidman, L. J., Poyurovsky, M., et al (2004) The neuropsychological basis of insight in firstepisode schizophrenia: a pilot metacognitive study. Schizophrenia Research, 70, 195-202.

Laroi, F., Fannemel, M., Ronneberg, U., et al (2000) Unawareness of illness in chronic schizophrenia and its relationship to structural brain measures and neuropsychological tests. Psychiatry Research, 100, $49-58$

Lewis, A. (1934) The psychopathology of insight. British Journal of Medical Psychology, 14, 332-348.

Lezak, M. D. (1995) Neuropsychological Assessment. New York: Oxford University Press.

Lipsey, M.W. \& Wilson, D. B. (200I) Practical MetaAnalysis. Thousand Oaks, CA: Sage.

Lysaker, P. \& Bell, M. (1994) Insight and cognitive impairment in schizophrenia - performance on repeated administrations of the Wisconsin Card Sorting Test. Journal of Nervous and Mental Disease, 182. 656-660.

Lysaker, P. H., Bryson, G. J. \& Bell, M. D. (2002) Insight and work performance in schizophrenia. Journal of Nervous and Mental Disease, 190, 142-146.

MacPherson, R., Jerrom, B. \& Hughes, A. (1996) Relationship between insight, educational background and cognition in schizophrenia. British Journal of Psychiatry, 168, 718-722.

Marks, K. A., Fastenau, P. S., Lysaker, P. H., et al (2000) Self-appraisal of illness questionnaire (SAIQ):

ANDRÉ ALEMAN, PhD, BCN Neuroimaging Centre, University Medical Centre Groningen, The Netherlands; NIRUJ AGRAWAL, MD, MRCPsych, Department of Neuropsychiatry, St George's Hospital, London; KEVIN D. MORGAN, PhD, ANTHONY S. DAVID, MD, MRCPsych, MRCP, Section of Cognitive Neuropsychiatry, Institute of Psychiatry, London, UK

Correspondence: André Aleman, BCN Neuroimaging Centre, Anton Deusinglaan 2, NL97I3 AW, Groningen, The Netherlands. Tel: +3l 503638798; email: a.aleman@med.umcg.nl

(First received 25 October 2004, final revision 23 August 2005, accepted 5 October 2005)

relationship to researcher-rated insight and neuropsychological function in schizophrenia. Schizophrenia Research, 45, 203-2II.

McCabe, R., Quayle, E., Beirne, A. D., et al (2002) Insight, global neuropsychological functioning and symptomatology in chronic schizophrenia. Journal of Nervous and Mental Disease, 190, 519-525.

McEvoy, J. P., Apperson, L. J., Appelbaum, P. S., et a (1989) Insight in schizophrenia. Its relationship to acute psychopathology. Journal of Nervous and Mental Disease, 177, 43-47.

McEvoy, J., Hartman, M., Gottlieb, D., et al (1996) Common sense, insight and neuropsychological test performance in schizophrenia patients. Schizophrenia Bulletin, 22, 635-64l.

Mintz, A. R., Dobson, K. S. \& Romney, D. M. (2003) Insight in schizophrenia: a meta-analysis. Schizophrenia Research, 61, 75-88.

Mohamed, S., Fleming, S., Penn, D. L., et al (1999) Insight in schizophrenia: its relationship to measures of executive functions. Journal of Nervous and Mental Disease, 187, 525-531.

Morgan, K. D. \& David, A. S. (2004)

Neuropsychological studies of insight in patients with psychotic disorders. In Insight and Psychosis (2nd edn), (eds X. F. Amador \& A. S. David), pp. 177-193. Oxford: Oxford University Press.

Nieuwenstein, M. R., Aleman, A. \& De Haan, E. H. F. (200I) Relationship between schizophrenia syndromes and neurocognitive functioning: a metaanalysis of CPT and WCST studies. Journal of Psychiatric Research, 35, 119-125.

Orwin, R. G. (1983) A fail-safe $\mathrm{N}$ for effect size in metaanalysis. Journal of Educational Statistics, 8, 157-159.

Pyne, J. M., Bean, D. \& Sullivan, G. (200I) Characteristics of patients with schizophrenia who do not believe they are mentally ill. Journal of Nervous and Mental Disease, 189, 146-153.

Rosenthal, R. (1991) Meta-Analytic Procedures for Social Research. London: Sage.

Rosenthal, R. \& DiMatteo, M. R. (200I) Metaanalysis: recent developments in quantitative methods for literature reviews. Annual Review of Psychology, 52 59-82.

Rossell, S. L., Coakes, J., Shapleske, J., et al (2003) Insight: its relationship with cognitive function, brain volume and symptoms in schizophrenia. Psychological Medicine, 33, III-II9.

Sanz, M., Constable, G., Lopez-lbor, I., et al (1998) A comparative study of insight scales and their relationship to psychopathological and clinical variables. Psychological Medicine, 28, 437-446.

Saravanan, B., Jacob, K. S., Prince, M., et al (2004) Culture and insight revisited. British Journal of Psychiatry, 184, 107-109.

Smith, T. E., Hull, J.W., Israel, L. M., et al (2000) Insight, symptoms and neurocognition in schizophrenia and schizoaffective disorder. Schizophrenia Bulletin, 26 193-200.

Startup, M. (1996) Insight and cognitive deficits in schizophrenia - evidence for a curvilinear relationship. Psychological Medicine, 26, 1277-1281.

Startup, M. (1997) Awareness of own and others' schizophrenia illness. Schizophrenia Research, 26 203-211.

Takai, A., Uermatsu, M., Ueki, H., et al (1992) Insight and its related factors in chronic schizophrenic patients: a preliminary study. European Journal of Psychiatry, $\mathbf{6}$, 159-170.

Upthegrove, R., Oyebode, F., George, M., et a (2002) Insight, social knowledge and working memory in schizophrenia. Psychopathology, 35, 34I-346.

Vaz, F. J., Bejar, A. \& Casado, M. (2002) Insight, psychopathology, and interpersonal relationships in schizophrenia. Schizophrenia Bulletin, 28, 3II-317.

Wang, M. C. \& Bushman, B. J. (1998) Using the normal quantile plot to explore meta-analytic data sets. Psychological Methods, 3, 46-54.

Wing, J. K., Cooper, J. E. \& Sartorius, N. (1974) The Measurement and Classification of Psychiatric Symptoms. Cambridge: Cambridge University Press.

Young, D. A., Davila, R. \& Scher, H. (1993) Unawareness of illness and neuropsychological performance in chronic schizophrenia. Schizophrenia Research, 10, 117-124.

Young, D. A., Zakzanis, K. K., Bailey, C., et al (1998) Further parameters of insight and neuropsychological deficit in schizophrenia and other chronic mental disease. Journal of Nervous and Mental Disease, 186, 44-50. 